\title{
Communitarianism 2.0: Austerity Protests and Political Participation on Social Media
}

\author{
KOSTAS MARONITIS, University of Greenwich
}

\begin{abstract}
Within the context of the financial crisis and austerity protests in Greece, this article elucidates the potential of Facebook communities to realise democracy as a notion that transcends instrumental processes of electing political elites while at the same time reinstating a cultural order and legitimising exclusionary political and communication practices. The article contrasts Facebook communities with John Dewey's vision of democracy as a form of social cooperation, which orients citizens toward pluralistic associations and overlapping political discourses. In order to overcome discredited economistic approaches, the article highlights the social dimension of the crisis by developing a media sociology for the analysis of the technological turn to community. The media sociology developed here refrains from sociology of media approaches, which explain the formation of social media communities as a result of hard variables such as the economy and political corruption. Media sociology will deploy social media communities for the analysis of the collective meanings of these variables. The article deals with the Facebook community 'Indignants in Syntagma'. The focus is on the activism of the movement from 25 May 2011 to 23 June 2012. Instead of Dewy's concept of democracy the Indignants' communities tend to forge a Web enhanced regime - defined here as Communitarianism 2.0. The direct democracy envisioned by this regime is closer to Schmitt's constitutional theory in which national and cultural homogeneity is a necessary precondition for the democratic exercise of any given political formation and authority.
\end{abstract}

\section{KEYWORDS}

Communitarianism 2.0, Indignants, John Dewey, media sociology, Carl Schmitt, Facebook, austerity protests, Greece, European Union, democracy.

\section{Introduction}

Mass media in Europe constantly remind their audiences that the markets dictate in unprecedented ways the services and welfare provided to citizens by the states. As a result, citizens of EU member-states under financial supervision perceive their governments not as their public servants but as those of other states, namely Germany, or of organisations such as the ECB, the IMF and the EU. The sociopolitical expectations that Eurozone members such as Portugal, Italy, Ireland, Spain and Greece are now facing from their new financial administrators are increasingly impossible to meet. Markets, the European north, and supranational organisations require that not just governments but also citizens should commit themselves to fiscal 
consolidation (Streeck 2011). European politicians and journalists have either dismissed political parties opposed to austerity as demagogues or insisted that those parties' election into government will effectively lead to chaos (Anon. 2012).

With the introduction of austerity measures and the unfolding of a multifaceted crisis - social, political and economic - the capacity of nation states to mediate between the rights of citizens and the requirements of financial administrators in exchange for access to the markets and membership to the Eurozone has been severely affected. Parliamentary procedures and elections in which citizens have no effective voice, generate perceptions of corruption, impartiality and betrayal, which may cause political disorder, from riots and occupations, to new and extreme political formations (Mason 2012).

Austerity protests in south Europe are mainly addressed according to the themes of hope and resistance. While theorists like Manuel Castells (2012) and Costas Douzinas (2013) acknowledge the surge of nationalism and xenophobia as by-products of defensive individualism and the widening gap between citizens and government, they view the values of this new political activism as progressive and transformative. By using the Spanish Indignants as one of his case studies, Castells argues for the vital importance of Internet communication for the creation of what he terms 'networks of outrage and hope': 'The more the movement is able to convey its message over the communication networks, the more citizen consciousness rises, and the more the public sphere of communication becomes a contested terrain' (Castells 2012, 237). Similarly, Douzinas views the resistance of the Greek and Spanish Indignants as an informal international solidarity against the suffering caused by the neo-liberal restructuring of national economies. The occupation of squares by the Indignants 'revived the direct democracy of classical Athens' (Douzinas 2013, 3) and provided the Left with a more positive even victorious orientation.

Yet, the progressive and transformative effects illustrated by Castells and Douzinas are not necessarily presented or even experienced by social actors within the framework of austerity protests; and the protesters might feel misrepresented or turn out to be offended by such observations. In contrast to these theoretical positions this article pays attention to the activities and critical competences of social media actors. The point here is to start from the social media actors' critical capacities and demands and use the sociological meanings of community and democracy in order to make them explicit.

The purpose of this article is two fold. First, considering that democracy as political value and institution is as much in danger as the economy if not more, it elucidates the potential of Facebook communities to realise democracy as a notion that transcends instrumental processes of choosing and electing political elites. The focus is on the Greek austerity protest movement 'Indignants in Syntagma' and on its Facebook presence and activities from $26^{\text {th }}$ of May 2011 to $23^{\text {rd }}$ of May 2012. Second, through a media sociological analysis, the article illustrates what kind of democracy and sociopolitical order the Facebook community of the Greek Indignants advocates by making use of their sense of justice, democracy and the discrepancy between politics and 
society as they are and as they should be in order to satisfy popular expectations. This is an attempt to analyse the media environment of political formations and mobilisations, ideas, emotions and institutions and the connections between them. This timeframe captures the formation and organisation of austerity protests under the Facebook aegis of the Indignants, the potential of Facebook communities to form public opinion and political consciousness outside of the confines of political parties and mainstream broadcast media up to the general elections of May 2012 which were stigmatized by the popular acceptance of the neo-Nazi party Golden Dawn.

\section{The Media Space of Protest and Indignation}

Sociologists and political officials initially perceived austerity and the crisis that followed as temporary social problems. Social discontent and violence should be battled by international agreements, negotiations between governments and trade unions and by means of responsive economic policy towards economic revival (Vaughan-Whitehead 2013). Yet, Michel Wievorka's (2012) reading of Edgar Morin's reflections on the concept of crisis indicates that the crisis should also have been examined according to its dynamic and transformative character. In the mid1970s, Edgar Morin, reflecting on a different type of capitalist crisis, considered crises to be events, which both reveal and have certain effects at the same time. Crisis is a moment of truth; an event that reveals what usually remains concealed and forces social actors and citizens alike to confront things that they do not want and never wanted to confront. Wieviorka (2012) in line with Morin, argues that the crisis reveals elements, which are constitutional parts of organisational structures and lived experiences and not just mere accidents. The crisis is not only a force of decomposition and disorganisation bur also a force of reorganisation, and transformation.

The most influential and documented of these new political formations materialised on the social and political platform Democracia Real YA (Real Democracy Now) in fifty Spanish cities on the $15^{\text {th }}$ of May 2011. Inspired and influenced by protests in Arab countries for civil society and parliamentary democracy participants demonstrated that it was possible to mobilise a great number of people in a short amount of time without many resources through the use of social media networks. These protests and their participants were later named 'The Spanish Revolution', and the 15-Movement also known as the Indignants. It was the latter name that provided an international dimension to protests against austerity measures in 675 cities around the world.

The novelty of the movement does not derive from its official political rhetoric as illustrated in their first manifesto: 'Democracy belongs to the people (demos=people, kratos=government) which means that government is made of every one of us. However, in Spain most of the political class does not listen to us' (Democracia Real Ya 2011). Democratic, advanced societies require 'the right to housing, employment, culture, health, political participation, free personal development and consumer rights for a healthy and happy living' (ibid.). The Indignants target a certain class of professionals as well as political incidents for the disintegration of social cohesion and of people's rights: 'concerned and angry about the political, economic and social 
outlook which we see around us: corruption among politicians, businessmen, bankers, leaving us helpless without a voice' (ibid.). The manifesto attempts to engulf political progressives and liberals as well as conservatives and people with undefined political ideologies therefore constructing a movement that is inclusive, apolitical and ultimately populist since it is comprised of and addressed to the people.

The Indignants in southern Europe formulate a new set of ideological beliefs and constitute a new political subjectivity in two distinctive yet interconnected ways. First, as opposed to traditional massive demonstrations and rallies, protesters camped in the city centres, like Madrid's Puerta del Sol and Athens' Syntagma Square reclaiming urban spaces from technocrats and businesses as spaces for the formation of public opinion. Second, the Indignants have used the Internet and its applications in a resourceful and different way compare to protests and political mobilisations of the past. Traditionally, the Internet served as a space for the distribution of information and organisation of demonstrations. Websites serving these particular purposes usually existed outside of the commercial domain. As Gerbaudo (2012) indicates, activists have always used websites like Indymedia as a depository of information on riots and protests. Contemporary activists and more specifically the Indignants are using corporate social networking sites for the organisation of their protests and dissemination of their ideas and consequently dissolving the boundary between digital and urban spaces, because they have made it possible to belong to and act in both simultaneously. The Indignants demonstrated that the only spaces where rejection of the austerity measures and political discussion seemed to be possible were the city squares and social networking sites as opposed to mainstream broadcast media and the parliament.

These changes signal a transition in the understanding of the role of networks. Geert Lovink (2011) suggests that current political events such as the protests against austerity measures and the appropriation of social media by movements such as the Indignants demand a different understanding of digital networks. Instead of focusing on the 'network organisation' - an instrumental view of networks as tools for organization, the dissemination of information, and the exchange of views and experiences - the focus should be on 'organised networks', which formulate identities, realise projects through collective action and problematise the space where politics is practiced.

\section{The Social Experiment of Real Democracy and the Community of Protest}

As becomes clear from the manifesto of the Indignants, the promise of living in an interconnected world through social media enhances the democratic possibilities of the excluded whose lives have been greatly affected by the imposition of austerity measures. The democracy envisioned in their statements and actions is a real democracy where the people have direct access to institutions through unregulated channels of communication and participation. The idea of a participatory, direct democracy has been the major epistemological concern of pragmatist sociologist John Dewey $(1989 ; 2011)$ whose theorising on democracy remains largely underexplored in the wake of social media protests. Dewey insisted on the importance of context and in particular on the need for democracy to emerge from the concerns, values and 
practices of groups. Democracy, therefore, is not a top-down affair and cannot be imposed through non-democratic procedures such as war and colonialism. In The Public and its Problems, Dewey (1989) sets out the task to reconstruct democratic communities and cultivate democracy in an epoch of global interactions. $\mathrm{He}$ illustrated the challenges democracy faces in a manner resonant with the Indignants' global appeal, the 'Facebook revolutions' and Europe's burgeoning problems:

The new era of human relationships in which we live is one marked by mass production for remote markets by cable and telephone, by cheap printing, by railway and steam navigation. Only geographically did Columbus discover a new world. The actual new world has been generated in the last hundred years. Steam and electricity have done more to alter the conditions under which men associate together than all the agencies which affected human relationships before our time (Dewey 1989: 323)

Dewey (1989) believed that the democratic action of citizens under these circumstances can be paralysed and he attempted to develop a model for the formulation of a better society - a 'Great Community' that can come into existence not only in theory but also in practice. The associated activity experienced in the spheres of global trade and communication require new ways of living together which would allow self fulfillment and community growth. States, publics and communities always evolve and they cannot simply be formed and conserved. Democracy in that respect appears to be an ongoing socio-political experiment towards collective improvement of methods of communication as well as the education of citizens for a better understanding of their interdependence with others.

Dewey's comments express a direct opposition to a conventional and at times banal understanding of democracy - democracy as a rational procedure of electing leaders, knowing and demanding civil rights and paying taxes. Democracy therefore should not be what has been already established as a mechanism that guarantees government legitimacy and change through free elections. Democracy should be a culture comprised of formal and informal rules, safeguarding over time individual and collective interests, the free expression of diverse opinions and most importantly their subsequent interplay. Democracy becomes the ideal form of social life where all actors realise the necessity to cooperate for their individual fulfillment. 'Democracy is more than a form of government; it is primarily a mode of associated living, of conjoined communicated experience' (Dewey 2011: 90).

In order to create more democratic relations between citizens and institutions Dewey identified three particular dispositions for the realisation of this ideal social life. Democracy should be conceived and approached 'experimentally', 'pluralistically' and 'fallibly' (2011); that is, democracy requires constant attention and reformulation. It is not a set of rules and regulations that can be passed from one generation to another. Each generation of citizens has to realise democracy according to their needs, problems and socio-political conditions. Drawing on the pragmatist orientation of his sociology, Dewy argued that ideas are tools with which to experiment. When they no longer work for the desired goal, citizens and social actors need to experiment with new ideas, relationships and modes of communication. 
In effect, Dewey's vision of democracy is based upon a commitment to sustain diverse ways of life and interaction amongst diverse cultural groups. The ongoing experimentation of ideas is followed by pluralistic thinking and by the desire to accommodate diverse viewpoints. There is not a unique or correct way to be democratic. Only through 'mutual respect' and 'mutual toleration' $(2011,303)$ can social actors learn to live together and at the same time achieve their individual and collective potential.

The beliefs that actors, political figures and institutions have with respect to the type of democracy needed may be flawed or perhaps too narrow and no longer viable. For Dewey (2011), no social or political theory can be wholly accurate and final and certainly cannot be applied to all social and political conditions. Ideas and theories derive from lived practice and they need to be constantly altered or even rejected according to relevant conditions. Fallibility will secure that all beliefs about democracy should be held cautiously instead of dogmatically.

The Indignants attempted to realise direct, participatory democracy and repair the torn social fabric not only through the use of organised networks but also within the ideological aspects of community. Yet, the discourse of community is not articulated as irretrievable and therefore utopian but as a concept that can be recovered and implemented. Community and communal relationships are seen by the Indignants as values and qualities that have been lost with the dominance of the markets in the economy and society, corrupt political systems and with the increasing governing role of impenetrable European institutions

The recovery of community within the protest politics of the Indignants is used as a concept that can unite people of diverse social classes and ideological inclinations against this encroachment. Antony Giddens' remarks on the reappearance of community in the political sphere perfectly illustrate the apolitical and inclusive character of the Indignants: 'on each side of the political spectrum today we see a fear of social disintegration and a call for a revival of community' $(1998,124)$.

In the past technology was seen as one of the reasons for the decline and disintegration of community. Yet there have been certain theorists who developed a theory of community that is not antithetical to technology, but, on the contrary, it is defined by and articulated through it. The works of Benedict Anderson (2006) and Howard Rheingold (1995) respectively are indicative of this trend. Anderson's concept of 'imagined communities' $(2006,9)$ as products of mass communication correlates the rise of the reading public in Europe with the birth of nationalism. In pre-print Europe and elsewhere in the world, Anderson argues that the diversity of spoken languages was so immense that it was not possible for print capitalism to exploit every single one of them. What happened instead was the formation of an assemblage of all those idiolects within a definite limit into far fewer in number print languages. According to Anderson, these languages provide the platform for national consciousness; they create a unified field of communication and cultural exchange 
between speakers of a huge variety of languages (a variety of French, English, Spanish and Greek) who might find it difficult or even impossible to understand one another in conversation but possible via print and paper. In the process, the reading public became aware of the thousands or even millions of people who read and write in the same language, but at the same time only those thousands or millions so belonged. 'These fellow readers, to whom they are connected through print, formed in their secular, particular visible invisibility, the embryo of the national imagined community' (Anderson 2006, 44).

Complementing the significance of media for the understanding and formation of community, Howard Rheingold's The Virtual Community (1995) studied the impact of the Internet on the formation of communities. Instead of supplementing existing human and organisational relationships, the Internet, according to Rheingold, offered a different level of interactivity. His enthusiastic response emanated from the Internet's ability to construct 'alternative realities' in relation to 'real' reality from which people could escape. Virtual communities are defined by Rheingold as 'social aggregations that emerge form the Net when enough people carry on those public discussions long enough, with sufficient human feeling, to form webs of personal relationships in cyberspace' $(1995,5)$. However, virtual communities are not exclusively the result of technological progress and of an enthusiastic public reception of the Internet but also of loss and recovery. Rheingold $(1995,6)$ notes that, 'one of the explanations for this phenomenon is the hunger for community that grows in the breasts of people around the world as more and more informal public spaces disappear from our real lives'. What is characteristic about Rheingold's theoretical framework and empirical analysis is that virtual communities are communities that exist on the Internet and not in everyday life. The postulation here is that the Internet enables the constitution of communities that would not exist otherwise. Following Rheingold's case studies it becomes evident that the participants of these virtual communities have decided to withdraw from an everyday life unfolding in an actual 'real' - space in order to be part of a utopian world of mutual understanding and strong emotional bonds. Consequently, virtual communities are superior to the increasingly diminishing actual ones.

The two theoretical formulations of community developed by Anderson and Rheingold both address community as something extraordinary instead of explaining how community has become a constitutive part of socio-political debates and also how it shapes understandings of political power. Anderson, in his definition of the nation as an 'imagined community', invests in a conceptual understanding of community by highlighting issues of belonging, (national) consciousness, comradeship and affinity but fails to address an actual one; patterns of behavior, habits and everyday life rituals are absent from Anderson's otherwise excellent correlation between media capitalism and nationalism. While Rheingold establishes a boundary between life on the Internet and actual everyday life, his observations focus on the habits and behavioural patterns of the participants of virtual communities.

Paradoxically his view of community derives from the conception of and belief in real communities. As a result, Rheingold undermines the novelty of virtual communities by presenting them as mediated technological versions of traditional ones. 
Instead of developing just another theoretical model of community that possibly addresses habits and behavioural patterns and at the same time extends beyond a traditional conceptions, I would like to address how community is understood and realised on the domains of protest politics and social media. Vera Amit and Nigel Rapport make the methodological suggestion that community should be employed as a broad concept that is 'good to think with' $(2012,4)$. The use of Facebook communities by the Indignants as an organisational and political platform encapsulates both the novelty of protest movements to use corporate media and the need to create and sustain organised networks of common experiences and interests. In 2010 Facebook, following through its mission to help 'people making connections', added the feature of 'Community Page'.

Community pages are a new type of Facebook Page dedicated to a topic or experience that is owned collectively by the community connected to it. Just like Official Pages for businesses, organizations and public figures, Community Pages let you connect with others who share similar interests and experiences. (Li 2010)

In the first instance, Facebook's explanation of community does not significantly differ from established theoretical definitions of community where certain important elements must be held in common. Values, norms, symbols, interests and experiences must be held in common but at the same time these elements constitute basic criteria for classification for community members as well as for outsiders. These definitions, including Facebook's attempt to define community for the promotion of its Community Page feature, do not necessarily raise any questions of when and how these elements are deployed in social interaction and in particular in times of crisis and political mobilisation. Yet, the activity of the Indignants on Facebook and the formation of their Facebook Communities do not only illustrate what sort of meanings, symbols and values must be held in common for reinvigorating democracy and defending sovereignty but also how what is held in common is deployed in social interaction for making sense of the crisis, of friends and enemies involved in the crisis and of how to assert a sense of national identity and belonging.

\section{Media Sociology and the Explanatory Potential of Community}

In order to think with the Indignants' Facebook communities and to explain how values, meanings and symbols are deployed in social media protests a certain methodological distinction needs to be established. Building on Jeffrey Alexander's (2006; 2011) cultural sociological foundations the Facebook communities of the Indignants should be approached by a media sociology as opposed to a sociology of media. Media sociology in that respect treats the presence and activities of the Indignants as never fully instrumental and rational in terms of realising (a Deweyan) direct democracy and repairing the torn social fabric. Instead they operate in a corporate media environment provided by Facebook that partially permits and partially allows social action and enables transformation or reproduction of the existing social and political structure. The media sociology developed here refrains from sociology of media approaches, which explain the formation of the Indignants' Facebook communities as a result of the uneven relationships in the Eurozone, the democratic deficit and political corruptions. Media sociology deploys Facebook 
communities for the understanding and analysis of collective meanings of these phenomena.

With the purpose of avoiding a purely economistic understanding and instead encapsulating social action beyond reason and deliberation the space of Facebook community is seen here as a public stage. On this stage, social actors project performances of their emotions, anxieties and aspirations to specific audiences whose response through the applications of 'Comment', 'Share' and 'Like' increasingly become legitimate references in socio-political conflict. Clifford Geertz's (1973) 'thick description' supplements media sociology by identifying the meaning particular social media performances have for protesters and then state what the knowledge from these meanings demonstrates about the society in which they are found. 'Thick description' establishes the analytical autonomy of media protest activities and then discovers how they intersect with other issues and institutions such as the economy, democracy and national identity.

\section{Indignation: 'To show them what it means to be Greek'}

Although austerity protests in Europe became synonymous with the Indignants there are noticeable differences in terms of the social setting and the political system in which they operate. Considering the extent to which the communication of indignation is more national than global, it unavoidably reflects the specificity of its national culture and political issues. The Greek Indignants declared their presence as a protest movement with the Facebook community Indignants in Syntagma. The occupation of Syntagma square and its inclusion in the name of the Facebook community provides an historical dimension to the actions of the movement as well as indicating its inclusive character. A square named after the Constitution that King Otto was obliged to grant due to popular and military demands on the $3^{\text {rd }}$ of September 1843 has now become the commercial epicentre of the city of Athens overseeing the Greek Parliament. On the $26^{\text {th }}$ of May 2011, Indignants in Syntagma uploaded 200 photographs to an album titled ' $26^{\text {th }}$ of May $2011^{\text {' }}$ referring to the protests and the occupation of the square on the same day. These 200 photographs, liked by just 81 Facebook users, depict Athens in a state of emergency; protesters and riot police occupy the streets of Athens where no daily routines and activities are visible. The photographs carefully portray protesters who do not fit the media stereotypes of the political activist as a rioter, dressed in black with their faces covered. These are ordinary citizens who occupy the square in order to express their indignation to politicians they previously trusted with their votes. On the $30^{\text {th }}$ of May, after another occupation of the square, the Indignants announced the purpose of their movement and its ideological and political foundations through their Facebook community page. Their announcement clarifies that the idea for this community was conceived by three eighteen year old men who managed to mobilise 'people of all ages, of all views, who most probably protested for their first time in their lives' (Indignants in Syntagma n.d.; May 30, 2011). ${ }^{1}$ The comments on this announcement

\footnotetext{
${ }^{1}$ Hereafter, when citing the Facebook Community Page of Indignants in Syntagma (n.d.), I will refer only to the date of the posting. When no name is given, the quotation is from the group's core team of administrators. When the posting was made by a specific individual outside of the page's administrators, I will also refer to their name.
} 
were irrelevant to the organisational aspect of the Indignants and they mostly focused on the moral integrity of politicians. ' 300 wankers, fascists have humiliated us across the planet, they have made us weak and cowardly. Don't you think it's time to show them what it means to be GREEK? Because surely they've never been GREEK!!!' (emi athanasopoulou; May 31 2011).

During the summer months of the same year, whenever no major political events or demonstrations were recorded, some of the comments expressed a particular type of nostalgia - a nostalgia correlated with the living standards of the Greek people prior to Greece's membership to the Eurozone in 2001. 'We want cheese pies that cost 50 drachmas' (June 3 2011) and a photograph of a coin of 1 drachma with the caption 'we want our little boat back' (ibid.) referring to the symbol on the face of the coin. Both posts received a considerable number of 'likes' (197 and 143 respectively) but the comments that followed dismissed this type of mentality as 'irrational' (Andreas Georgiadis June 3 2006) and 'hyperbolic' (Velmahos Ioannis; June 3 2006).

Towards the autumn months of 2011, trade unions and protest movements were back in action. What is noteworthy from that period is that Indignants in Syntagma had morphed into a stage upon which Facebook users could announce events and comment on issues that were not directly associated with austerity and corrupt politicians. A popular topic of conversation in September 2011 was the inability of the Ministry of Education to produce school DVDs with the Greek alphabet. Reactions to this news item fluctuated from comments on the ignorant government due to the Prime Minister, George Papandreou's American upbringing (Stefanos Serafeimidis; September 20 2001) to suggestions that pupils should not attend classes until the Ministry produces DVDs with the Greek Alphabet (Nikos Tsalous; September 20 2001). During the first days of October 2011, social media comments were preoccupied with the occupation of squares on a pan-European level on $15^{\text {th }}$ of October. Indignants in Syntagma uploaded posters reading 'World Revolution Now/We Demand a Real Democracy/For The People By The People' and 'The Whole World a Single Square' (October 11 2011). There was a clear attempt to align the Greek Indignants not only with other Europeans subjected to austerity cuts but also with citizens around the world who demand a real, participatory democracy. On October 12, the administrators of the community pled for political mobilisation and activism: 'each and every one of us should send invitations to friends and acquaintances and disseminate on (Facebook) walls Saturday's protests. The time has come for mobilisation and awakening' (October 12 2011). Facebook users responded enthusiastically to this call and expressed the need to 'protest everyday against the global dominance of the banks' (Zoi Zoiri Darcy; October 12 2011) and demanded a dynamic presence in the protest in order to measure their powers against 'the deep state' (Pad A Zos; October 12 2011).

Days after the occupation of the square and the violent clashes between riot police, the Indignants and other activists, the page's administrators posted a digitally manipulated photograph of the Prime Minister George Papandreou wearing a bulletproof vest carried violently by policemen most probably to the court or jail; 'a day of magic' (October 23 2011) was the title given to the photograph, which was 
'liked' by 535 Facebook users. Further proof of the solidarity amongst Greeks against the Troika and the political establishment was provided in photographs showing football fans expressing their indignation in stadia around Greece. The comments on these photographs were very supportive regardless of club affiliations and rivalries. An administrators set the mood by posting 'even though I support Olympiacos I would like to congratulate the fans of Panathinaikos' (October 23 2011). The Panathinaikos fans were holding a banner that read 'Criminal politicians, Parliament of the Wealthy you will be drowned by the rage of the outraged'.

The national holiday of the $28^{\text {th }}$ of October also known as the anniversary of the 'NO' when Greeks commemorate the rejection by the dictator and Prime Minister of Greece Ioannis Metaxas of the ultimatum made by Benito Musolini in 1940 to allow Axis Forces to occupy strategic positions in Greek territory provided the opportunity to view the crisis through the prism of history. Schools and the military take part in this commemoration by parading in major streets. The administrators uploaded photographs of pupils purposefully ignoring the Minister of Education while parading in the streets of Athens. 'Worthy descendants of the 1940 fighters. Dedicated to the memory of my grandfathers... Congratulations to this proud new generation, HOPE and FUTURE of this country' (Stella Amarantou; October 28 2011). Some endorsed the pupils' actions because the Minister for Education 'is an atheist' (Katerina Papadimitriou; October 28 2011) while others perceived their gesture as a quintessentially Greek - 'a taste of Greece you little ass Americans' (George Paralogue; October 28 2011).

In February 2012, students, trade unions, political activists and the Indignants were preparing for another round of protests, riots and occupations. The Community updated its status: 'TAKE YOUR FRIENDS, MAKE APPOINTMENTS...NO ONE AT HOME. WE DEMONSTRATE OUR RIGHT IN THE STREETS' (February 12, 2012). For the first time since the conception of the Greek Indignants there were open disputes regarding the method of action but not necessarily about the political orientation of the movement. Some of the eighteen comments on this update focused on how foreign media report violent confrontations in Athens by stating that 'THERE IS NO REASON TO LOOK LIKE FOOLS INTERNATIONALLY WE CAN DEMONSTRATE IN ALL CITIES PEACEFULLY TO SEND A MESSAGE WE DEMAND SOLUTIONS AND GUARANTEES FOR THE FUTURE' (Stathis Vonitsanos; February 12 2012). The next day, while the demonstrations and the riots continued the Community attempted to distance itself from rioters and violent activists. Again, the way the Indignants are perceived and represented by international media appears to be of paramount importance: 'All English speaking media provide unsubstantial reports - they report we burn our historical monuments!' The administrators attach a YouTube video in order to prove their peaceful actions and intentions of their movement. The footage of the video is explained by commentary written in English: 'look who burn the city, the cars and tha business in the center of Athens, while Greek people protesting peacfull, a team of cops whent trought them and start fighting with them [sic]' (February 13 2012). 
Facebook users indicated that Syntagma as an iconic place had lost its momentum and photographs of the square occupied by Indignant citizens are no longer motivational. Instead, they suggested that they should be congregating in neighbourhoods and local streets (Kostas Fontalis; February 13 2012). Yet, the Community kept active by expressing its dissatisfaction with the medium of television (February 29 2012); demanding from the British government to give back the Elgin marbles (ibid.); and reasserting a sense of Greek cultural superiority by mocking the sartorial choices and eating habits of German tourists in Greece (April 30 2012).

In May the focal point of all media was the national legislative elections. National elections were due to be held in late 2013, four years after the previous elections. The inability of the governing Social Democratic Party to maintain a majority in the parliament as well as implementing the austerity measures due to a continuous social unrest led to the elections of May 6 2012. While the only coherent political views expressed by the Indignants amounted to an aggressive sense of patriotism and hostility towards the political establishment of Europe and of Greece, they wanted to make sure that the elections would adhere to constitutional standards. 'IF YOU SEE FOREIGNERS AT ANY ELECTION CENTRE CALL THE POLICE. ACCORDING TO LAW 3838/2010 FOREIGNERS ARE NOT ALLLOWED TO VOTE' (May 5 2012). Regardless of the validity of this claim 175 users liked this update. The comments that followed acknowledged that major political parties used to deploy undocumented migrants for boosting their percentages in exchange for their regularisation (Konstantinos Z; May 5, 2012) but also the impossibility to differentiate between legitimate and illegitimate voters (Leonidas Siozos; May 5 2012).

On the day of the election the activities of the Community were limited to the announcement of the election results and to sporadic comments on the voting patterns of the Greek citizens. Even though there was no clear winner and for the first time in years a party of the Left - The Coalition of the Radical Left - came second with 16.79 per cent of the vote there was a sense of disappointment. Not only because the political establishment maintained some of their power but also because the neo-Nazi party Golden Dawn received 6.97 per cent of the vote. Most of the commentators understood the rise of a neo-Nazi party as a by-product of our 'non-democratic' times supported by European officials (Giota Grammenou; May 7 2012). A few were of the opinion that an extreme party might provide a shock to the political system and to hold to account corrupt politicians (Manolis Grigoratos; May 7 2012).

On May 232012 the Indignants marked one year of protests, occupations and most importantly indignation with the political establishment. The Community commemorated its birthday with a status update entitled, 'One year on the birth of the idea of the Indignants'. The text that accompanies this update attempts to appraise the presence and achievements of the movement. Yet this text is different in tone than the previous communication of the Community. There is a sense of defeat and the first person collective pronoun is at points replaced by the more personal and authoritative 'I': 
I first created the event Indignants in Syntagma, which in two days had attracted 10,000 people. Despite the initial and still unexplained removal of our Community from Facebook people got stubborn and they declared their presence in Syntagma in a vibrant and dynamic way. The movement continued to expand and managed to mobilise more than 200,000 people regardless of ideologies, political parties and beliefs and expressed their indignation to the political system, corrupt politicians and parties. (May 23 2012)

At this point, the author acknowledges that at the end politicians did not respond productively to this massive mobilisation. After months of protesting and occupying Syntagma politicians 'were either dismissive or ignoring the movement' (ibid.). Consequently, 'some decided to end this apolitical and peaceful movement by using violence' (ibid.). In the end, they claim, the police started terrorising ordinary people by attacking the elderly and children. 'Looking back at these incidents I wonder about the state of democracy in our country' (ibid.). The author concludes by expressing how proud he is of 'all those people who took part in this movement' and he hopes that 'our country will come out of the economic swamp' so all of us 'can look at the future with optimism and hope' (ibid.). Most of the 17 comments by Community members referred to the movement as something of the past that nevertheless was very important for 'giving a voice' to individuals (Meletis Kechaidis; May 23 2012) and for 'excluding communists and trade unionists' from their protests (Kostas Archontakis; May 23 2012).

\section{Order and Democracy in the Facebook Community}

The meanings of the Indignants' socio-political performance manifest themselves through binary codes that categorise people, behaviours and ideas in moral terms: as good and bad, as pure and impure, as moral and immoral. When these evaluations of politicians, policies and institutions are entangled within practices of communication and community formation, they structure the narrative of indignation. At the core of this narrative exists the desire for real democracy in opposition to parliamentary democracy as practiced by corrupt politicians. Even though the social performance of the Indignants indicates that the movement operates in opposition to parliamentary democracy it does not reject every single aspect of it. What has been rejected altogether is guidance provided by political parties and trade unions due to their perception as the main agents of corruption. This rejection is ensued by the constant expression of negative sentiments instead of supporting a particular political formation or an emerging political subjectivity. The discontent of the Indignants towards financial administrators and politicians in conjunction with derogatory characterisations of powerful nations such as the Americans and the Germans largely delineate the character of the movement and its activities on Facebook.

By situating themselves in opposition to an established political system defined and supported institutionally by Parliamentary democracy, the activity of the Indignants on Facebook illustrates the possibility of direct participation, intervention and expression. Whereas European officials, politicians and their parties are struggling to promote a single coherent view on the current crisis and on the terms of the Greek bailout by the Troika, the Indignants relied on the promotion of personal views freed from hierarchical structures and the necessity of concluding in common positions. 
In that respect, the real democracy envisioned by the Indignants only partially and selectively is compatible with Dewey's $(1989 ; 2011)$ conceptual understanding of democracy. Similar to Dewey, the Indignants realise the need for democracy to emerge from the concerns, values and practices of cultural groups. It becomes evident that the top-down affair of selecting political representatives and administrators, paying taxes and exercising political rights has given its place to a mode of associated living and to a conjoined communicated experience. Still, Dewey's 'Great Community' that can come into existence through democratic practice requires the acknowledgement of diverse ways of life and interaction amongst diverse cultural groups. The Facebook community Indignants in Syntagma uses a national, majoritarian frame in order to comprehend and oppose the austerity politics. The activity of the community aims at the revival of collective memories shaped by former crises and war conflicts such World War Two and the military junta in order to name, blame and shame those being held responsible for the current crisis and the subsequent politics of austerity. Indignants in Syntagma, although apolitical and antiestablishment in character, also appears to be xenophobic and anti-European, offering the most nationalistic understandings of and solutions to the crisis. Even though many community members and other Facebook users were disappointed by the increasing popularity of the neo-Nazi party Golden Dawn, the xenophobia towards Europeans and especially Germans, and the appointment of national pride as a virtue and as a means to opposing austerity (in conjunction with the rejection of parliamentary democracy), legitimised the rhetoric and practices of the extreme new Right in Greece. This legitimation does not only refer to the electoral surge of extreme parties like Golden Dawn but also to the process of presenting nationalism, xenophobia and rejection of parliamentary democracy as views held by the majority of Greek people.

Focusing exclusively on harms emanating from disembedded markets and 'unpatriotic politicians' the Indignants purposefully ignored harms originating elsewhere, namely in the community they aspired to constitute. Such a focus created a smokescreen for a specific type of activism, which at same time was an instrument of xenophobia and exclusion. The Facebook Community Indignants in Syntagma points towards the creation of a total cultural and political order by targeting and opposing external factors to the national majority. The order of the Indignants' community does not direct its members to pluralistic associations but instead to a particular type of a Web 2.0 enhanced regime, which I call Communitarianism 2.0.

As a regime, Communitarianism 2.0 neither distances itself from participatory democracy nor ignores the potential of social media to mobilise the people and express majoritiarian views. Instead Communitarianism 2.0 is closer to Carl Schmitt's (2000) politics of sovereignty and democratic legitimacy than Dewey's (1989; 2011) social experiment towards collective improvement of communication between diverse groups of people. Schmitt's political theory has always been suspicious of the procedures of liberal democracy such as individual voting rights, the secret ballot and political representation. The belief in what Schmitt (2000) calls 'parliamentarism' government through political debates - belongs to the intellectual tradition of liberalism and has nothing to do with democracy. A true democratic regime as illustrated by Schmitt (2000) becomes political and exhibits its power by knowing 
how to refuse or ward off something foreign and unequal that threatens its homogeneity. It is essential to distinguish between the foreigner as a legitimate collective enemy, with whom power relations are established on the basis of equality or competition according the political and economic division of the world, and the illegitimate interior enemy who disrupts a political, social and cultural order and must be eliminated.

Despite their proclamations of being an apolitical movement, the Indignants are quintessentially a political movement by making the distinction between friend and enemy. Indignants in Syntagma contextualises the leading Eurozone members and intranational institutions as legitimate enemies with respect to the structure of the Eurozone and the imposition of austerity politics and at the same time targets the national political establishment as the interior enemy for not sharing the same civic virtues with the majority, and for not being able to protect the majority in question against their (legitimate) political and economic European enemies. The identification of both legitimate and illegitimate enemies and their subsequent contextualisation as heterogeneous elements is a vital process for the functioning of any true democracy. Communitarianism 2.0 in synch with Schmitt's political theory exploits the interactive features of Web 2.0 and Facebook in particular for keeping at a distance or eliminating from political participation everything and everyone that threatens homogeneity such as the Euro, trade unions, political parties, European people, and the undocumented migrant voter. 'The equality of all persons as persons is not democracy but a certain kind of liberalism, not a state form but an individualistichumanitarian ethic and Weltanschauung' (Schmitt 2000, 13).

The apparent lack of hierarchical structures, the openness to participation, the national majoritarian view, the constant motivation to overcome passivity, and most importantly the direct democratic organisation of the Indignants ultimately attempt to define 'the people' and be 'the people'. Within Communitarianism 2.0 'the people' express themselves directly as a mass by opposing austerity and its political agents without creating the impression they want to play the role of the expert. Nevertheless, their lack of scientific or political expertise does not prevent them to appear as the sovereign subject and in extension to challenge parliamentary democracy. Schmitt (2000) argues that the attempt of liberal constitutions to dispense the bearer of sovereign authority has not been and cannot be successful because there cannot be a functioning legal order without one. In liberal democracies, the people are subject only to the determinate and predictable demands of the law, and not to the authority of specific individuals. But the law in order to be effective there needs to be an authority that deals with issues arising out of disputed interpretations. Yet the content of the law does not determine the bearer of sovereignty but instead a sovereign authority needs to exist prior to the law itself. The Communitarianism 2.0 of the Indignants is a contemporary call for a strong popular executive power unconstrained by the legality of the police, national governments and of European institutions.

The sovereign subject for Schmitt (2000) is always the subject who has the power and takes the decision to create a new constitutional order. From the beginning of the protest against austerity up to the general elections of 2012 the Greek Indignants 
through their Facebook community became the bearers of sovereignty by creating a new communication order in which national and cultural homogeneity is the necessary precondition as well as virtue for protest and political participation.

\section{Conclusion}

This article has examined the potential of a Facebook protest community to realise direct, participatory democracy. Focusing on the critical capacities and demands of the social media actors the article has argued that instead of a network of hope and a revival of classic Athenian democracy, the Indignants in Syntagma constituted a Web enhanced communication regime best understood as Communitarianism 2.0.

Communitarianism 2.0 facilitates direct intervention and acknowledges the need for democracy to emerge out of concerns and habits but this democracy can only be practiced by a national homogeneous group and can only be directed against external and internal enemies.

The unwillingness of government and political authorities to apprehend social media protest communities cements the view that democracy can only be practiced by administrative guidelines and elections and condemns protest communities to exist on the margins of civil society. Indignants in Syntagma attest to the need and urgency of direct political participation and of an active citizenship facilitated by a particular technological infrastructure despite their anxieties over mainstream media representation and acknowledgement by formal political authorities. The nationalistic and xenophobic frame of the community's arguments and demands does not necessarily stimulate democracy as the outcome of the elections pointed out but indicates the limitations of parliamentary democracy and new sites for the formation of public opinion. 


\section{References}

Alexander, J. C. (2006) The Meanings of Social Life: A Cultural Sociology, Oxford: Oxford University Press

--- (2011) Performance and Power, Cambridge: Polity Press

Amit, V. and Rapport, N. (2012) Community, Cosmopolitanism and the Problem of Human Commonality, London: Pluto Press

Anderson, B. (2006) Imagined Communities: Reflections on the Origin and Spread of Nationalism, London: Verso

Anon. (2012) 'Widersteht den Demagogen', Financial Times Deutschland, [online], June 16. Accessible at http://www.ftd.de/politik/europa/:wahlempfehlungantistatheite-sto-dimagogo-widersteht-den-demagogen/70050480.html

Castells, M. (2012) Networks of Outrage and Hope: Social Movements in the Internet Age, Cambridge Polity Press

Democracia Real YA! (2011), 'Manifesto (English)', DemocraciaRealYA.es, [online]. Accessible at http://www.democraciarealya.es/manifiesto-comun/manifestoenglish/. Accessed 8 November 2013

Dewey, J. (1989) The Public and its Problems, Ohio: Ohio University Press

--- (2011) Democracy and Education: An Introduction to the Philosophy of Education, South Carolina: Simon and Brown

Douzinas, C. (2013) Philosophy and Resistance in the Crisis: Greece and the Future of Europe, Cambridge: Polity Press

Geertz, C. (1973) The Interpretation of Cultures, New York: Basic Books

Gerbaudo, P. (2012) Tweets and the Streets: Social Media and Contemporary Activism, London: Pluto Press

Giddens, A. (1998) Beyond Left and Right: The Future of Radical Politics, Cambridge: Polity Press

Indignants in Syntagma (n.d.) [АГАNАKTI $\Sigma$ MENOI $\Sigma$ TO $\Sigma$ YNTAГMA], Facebook Community Page, [online]. Accessible at https://www.facebook.com/AganaktismenoiStoSyntagma?fref=ts. Accessed 16 September 2013

Lovink, G. (2011) Networks Without a Cause: A Critique of Social Media, Cambridge: Polity Press

Mason, P. (2012) Why It's Kicking Off Everywhere: The New Global Revolutions, London: Verso

Rheingold, H. (1995) The Virtual Community: Finding Connection in a Computerized World, London: Minerva

Schmitt, C. (2000) The Crisis of Parliamentary Democracy, trans. E. Kennedy, London: MIT Press

Streeck, W. (2011) 'The Crises of Democratic Capitalism', New Left Review, 71, September - October 2011, 5-29 
Li, A. (2010) 'Connecting to Everything You Care About', The Facebook Blog, [online], 19 April. Accessible at

http://blog.facebook.com/blog.php?post=382978412130. Accessed 7 November 2013

Vaughan-Whiehead, D. (2013) 'Public Sector Shock in Europe: Between Structural Reforms and Quantitative Adjustments', in D. Vaughan-Whitehead (ed.), Public

Sector Shock: The Policy Retrenchment in Europe, London: Edward Elgar Publishing, pp. $1-42$

Wievorka, M. (2012) 'Financial Crisis or Societal Mutation?', in M. Castells, J. Caraça and G. Cardoso (eds), Aftermath: The Cultures of the Economic Crisis, Oxford: Oxford University Press, pp. 82-104 